INTERNATIONAL JOURNAL OF RESEARCHES IN BIOSCIENCES, AGRICULTURE AND TECHNOLOGY (C) VISHWASHANTI MULTIPURPOSE SOCIETY (Global Peace Multipurpose Society) R. No. MH-659/13(N) www.vmsindia.org

\title{
SYNERGISTIC SOLVENT EXTRACTION STUDY OF FE(III) FROM SODIUM ACETATE BY USING DB18C6 AND TBP
}

\author{
G. H. Nikam ${ }^{1}$, S. R. Sabale ${ }^{1}$ and B. V. Tamhankar ${ }^{2}$ \\ ${ }^{1}$ Department of Chemistry, Jaysingpur College, Jaysingpur, Dist. Kolhapur (MS), INDIA -416 101 \\ 2 Department of Chemistry, Willingdon College, Sangli (MS), INDIA \\ sgurunath.nikam@gmail.com
}

\begin{abstract}
:
In the present work synergistic solvent extraction of Fe(III) has been investigated with TBP and DB18C6 in kerosene from sodium acetate medium. The various parameters for quantitative extraction and separation of $\mathrm{Fe}(\mathrm{III})$ such as concentrations of sodium acetate, nature of diluent, shaking time, stripping agents and effect of foreign ions where determined. The synergistic effect of TBP and DB18C6 concentrations on extraction has been studied. The analytical conditions for quantitative separation of Fe(III) from various ternary mixtures containing $\mathrm{Ni}(\mathrm{II}), \mathrm{Co}(\mathrm{II}), \mathrm{Mn}(\mathrm{II})$ and $\mathrm{Bi}(\mathrm{II})$ ions where also studied. The method was extended for extraction and separation of Fe (III) from soap samples. Developed analytical method is advantageous over previous methods as it is simple, rapid and selective with good reproducibility.

Keywords : Synergistic extraction, DB18C6, TBP, Fe(III), sodium acetate, kerosene
\end{abstract}

\section{Introduction:}

The selective separation of iron(III) from undesired impurities is an important issue for the concentration or purification of secondary sources. The separation and determination of iron in mineral objects and also the concentration of other basic rock forming elements are of great importance in mineralogy, petrology and associated disciplines. Iron always accompanies with copper, zinc, nickel, cobalt and other metals and therefore the separation of iron from other metals is an important problem in hydrometallurgical processes. Since Co and $\mathrm{Ni}$ belong to the iron series elements, they are very similar in qualities and often influence the determination of $\mathrm{Fe}$. The development of new processes for the recovery of iron is the need for utilization of secondary sources as raw materials. Thus, there is a demand for an inexpensive, simple and selective procedure for the separation determination of iron. It is still interesting to develop a simple, sensitive and selective method for the separation of iron.

Solvent extraction of iron(III) from acidic aqueous solutions using TBP allow selective removal containing $\mathrm{Mn}(\mathrm{II}), \mathrm{Ni}(\mathrm{II}), \mathrm{Co}(\mathrm{II})$, and $\mathrm{Cu}(\mathrm{II})$ [1]. The use of N,N O-tetra substituted malonamides for the extraction of iron(III) from acid chloride solutions has been investigated [2]. The distribution equilibrium of iron(III) between bis(2-ethylhexyl) phosphinic acid dissolved in hexane and acidic aqueous nitrate media has been investigated [3]. Solvent extraction of iron from photographic waste using cyanex 272, cyanex 302 and D2EHPA has been proposed by Othman [4]. The extraction of iron(III) has been studied from chloride solutions with D2EHPA, cyanex272 and its sulfur substituted analogs such as cyanex 302, cyanex 301 and Aloxime
800 [5], D2EHPA, PC 88A, cyanex 272 and their mixtures [6] has been studied. The liquid liquid extraction of $\mathrm{Fe}(\mathrm{III})$ solution from the sulfuric acid medium has been proposed by using a partially neutralized extractant solution of 30\% cyanex 272 and 30\% TBP in ESCAID 110 [7]. The separation of iron(III) from chloride solutions at macro level concentration by different solvents such as TBP, D2EHPA and their mixture has been investigated [8-10]. The utility of Cyanex 272 for the separation of iron and chromium from a tannery filtrate has been demonstrated [11]. Selective extraction and separation of $\mathrm{Ti}(\mathrm{IV}), \mathrm{Fe}(\mathrm{III})$, and $\mathrm{Mg}$ (II) in the three liquid phase system containing TRPO, PEG and $\left(\mathrm{NH}_{4}\right)_{2} \mathrm{SO}_{4}$ was achieved by adding EDTA [12]. Liquid liquid extraction and separation of iron(III) with PC 88A in toluene [13-17], TBP, MIBK [18], TOPO and Cyanex 923[19,20] have been extensively studied. Cierpiszewski et al. have studied the extraction of zinc(II), iron(II), and iron(III) with phosphate compounds from hydrochloric acid solutions [21-23]. It is reported that polymeric pseudo crown ethers, incorporating oxyethylene and oxypropylene units, extract $\mathrm{FeCl}_{4}^{-}$from mixed hydrochloric and phosphoric acids [24]. The solvent extraction and transfer through a bulk liquid membrane of chromic acid in sulphate media by DC18C6 in dichloromethane has been studied [25]. Extraction of iron(III) with DC18C6, DB18C6, and 18C6 from $10 \mathrm{M}$ hydrochloric acid solution has been studied [26].

But there was no attempts for the synergistic solvent extraction study of $\mathrm{Fe}(\mathrm{III})$ using DB18C6 and TBP compounds. In the present work solvent extraction of $\mathrm{Fe}$ (III) from sodium acetate media using mixture DB18C6 and TBP in kerosene has been carried out. The 
aim of this study was to achieve quantitative extraction of $\mathrm{Fe}$ (III) using low concentrations of DB18C6 and TBP. Number of existing methods for separation of $\mathrm{Fe}(\mathrm{III})$ using different systems have drawbacks such as long equilibrium time, difficult phase separation, multiple extractions, mutual solubility of two phases, etc. The advantages of this method over the reported methods are, use of kerosene as solvent, concentration of DB18C6 and TBP required for quantitative extraction is low and a clean cut separation of $\mathrm{Fe}(\mathrm{III})$.

\section{Materials and Methods: Instrumentation}

The metal ion concentrations were determined with the help of UV Visible spectrophotometer (Model UV 3000+, Labindia Analytical Instrumentations), Flame photometer (Model EQ 850, Equiptronics) and Atomic absorption spectrometer (Perkin-Elmer). A digital pH meter (Model EQ 610, Equiptronics) and a wrist action mechanical flask shaker were used for experimental procedure.

\section{Reagents}

The Dibenzo 18 Crown 6 (DB18C6) from Spectrochem, Tributyl Phosphate (TBP) from Sd Fine Chemiclas and Sodium acetate (AnalaR grade, Merck) were used as received without any further purification. Standard stock solution containing $5 \mathrm{mg} / \mathrm{ml}$ of $\mathrm{Fe}$ (III) was prepared by dissolving $2.420 \mathrm{~g} \mathrm{FeCl} 3.6 \mathrm{H}_{2} \mathrm{O}$ (AnalaR grade, Merck) in $100 \mathrm{~mL}$ of doubly distilled deionised water and standardized gravimetrically by a known method [27]. A solution containing $50 \mu \mathrm{g} / \mathrm{mL}$ of $\mathrm{Fe}$ (III) was prepared by appropriate dilution of the standard stock solution. Kerosene available in local market was used after distillation.

\section{General Procedure}

An aliquot of $\mathrm{Fe}(\mathrm{III})$ solution $(1 \mathrm{~mL}$ of $50 \mu \mathrm{g} / \mathrm{mL}$ ) was mixed with sodium acetate to make it's concentration of $0.01 \mathrm{M}$ in a total $10 \mathrm{~mL}$ of the solution. This solution was equilibrated with 10 $\mathrm{mL}$ of extractants contatining $0.001 \mathrm{M}$ TBP and $0.0001 \mathrm{M}$ DB18C6 in kerosene taken in separating funnel. After shaking for 5 minutes, the two phases were allowed to settle and separate. After separating two phases, Fe (III) was back extracted from organic phase by shaking with $10 \mathrm{~mL}$ of $4.0 \mathrm{M}$ perchloric acid and was estimated by spectrophotometrically using ammonium thiocyanate [28]. These results were confirmed by matching the results with AAS analysis. All the experiments were carried out at room temperature.

\section{Synergistic solvent extraction of Fe(III) using DB18C6 and TBP}

Solvent extraction of $\mathrm{Fe}(\mathrm{III})$ using DB18C6, TBP and their mixture in kerosene as diluent was studied from $0.01 \mathrm{M}$ sodium acetate medium. In this experiment extraction of Fe(III) using DB18C6 in kerosene was carried out by varying its concentration from 0.00001 to $0.0002 \mathrm{M}$. Then extraction of $\mathrm{Fe}(\mathrm{III})$ using mixture of $0.001 \mathrm{M}$ and varying concentrations of DB18C6 in the range 0.00001 to $0.0002 \mathrm{M}$ in kerosene was carried out. The results indicating the extraction of $\mathrm{Fe}(\mathrm{III})$ using mixture of DB18C6 and TBP was increases with DB18C6 concentration and it was quantitative from 0.00009 to $0.0002 \mathrm{M}$ DB18C6. However the extraction of $\mathrm{Fe}(\mathrm{III})$ was increases with increasing concentration of DB18C6 but there was no quantitative extraction with only DB18C6 in the concentration range 0.00009 to $0.0002 \mathrm{M}$ (figure 1).

Then extraction of $\mathrm{Fe}(\mathrm{III})$ from $0.01 \mathrm{M}$ sodium acetate using TBP was carried out by varying its concentration from 0.0001 to 0.002 in kerosene. After that extraction of $\mathrm{Fe}$ (III) using mixture of $0.0001 \mathrm{M}$ DB18C6 and varying concentrations of TBP in the range of 0.0001 to 0.002 in kerosene was carried out. In this experiment it was observed the extraction was quantitative with mixture of $0.0001 \mathrm{M}$ DB18C6 and 0.0009-0.002 M TBP. Extraction was not quantitative with only TBP (figure2). For further extraction study mixture of extractants contatining $0.001 \mathrm{M}$ TBP and $0.0001 \mathrm{M}$ DB18C6 in kerosene was used.

Effect of sodium acetate concentration on extraction of $\mathbf{F e}$ (III)- The effect of sodium acetate concentration on the extraction of $\mathrm{Fe}$ (III) was studied by varying concentration of sodium acetate in the wide range of concentration from 0.001 to $0.014 \mathrm{M}$. The study shows that using mixture of $0.001 \mathrm{M}$ TBP and 0.0001 M DB18C6 in kerosene extraction efficiency was increases with sodium acetate concentration and it was quantitative from 0.006 to $0.014 \mathrm{M}$ sodium acetate (Figure 3), so for further investigation $0.001 \mathrm{M}$ sodium acetate was used.

Selection of stripping agent - Back extraction of $\mathrm{Fe}$ (III) complexed in the organic phase was carried out using various mineral acids such as nitric acid, perchloric acid, sulphuric acid. Effect of various stripping agents on extraction of $\mathrm{Fe}$ (III) is shown in figure 4. The stripping of Fe(III) was found to be quantitative with 7.0 to $8.0 \mathrm{M}$ nitric acid, 4.0 to $8.0 \mathrm{M}$ perchloric acid while stripping was found to be incomplete with

\section{Results and Discussion:}


hydrochloric acid acid. For further studies $4.0 \mathrm{M}$ perchloric acid was used as a strippant.

\section{Choice of diluent}

A various solvents such as toluene, xylene, nitrobenzene and kerosene were employed to discern the effect of varying nature of the organic diluents on the extraction of $\mathrm{Fe}(\mathrm{III})$. As apparent from the data the percent extraction of Fe(III) was quantitative with kerosene only. It was incomplete with xylene $(30 \%)$, toluene $(68 \%)$ and nitrobenzene $(75 \%)$. However, there is no any definite correlation between percent extraction and dielectric constant of solvent.

\section{Period of equilibration}

The extraction of Fe(III) from $0.01 \mathrm{M}$ sodium acetate by $10 \mathrm{~mL}$ of extractants contatining $0.001 \mathrm{M}$ TBP and $0.0001 \mathrm{M}$ DB18C6 in kerosene was carried out with varying periods of shaking from 1 to 15 minutes. The extraction was completed within 5 minutes of shaking, which was employed throughout further investigation. However, prolonged shaking has no adverse effects on the extraction efficiency.

Effect of foreign ions on extraction efficiency Different amounts of diverse ions were added to $50 \mu \mathrm{g}$ of $\mathrm{Fe}(\mathrm{III})$ and mixture was extracted according to procedure. The tolerance limit of an ion was taken as maximum amount causing an error not greater than $\pm 2 \%$ in the extraction of iron(III). Most of the metal ions shows very high tolerance limit. The cations and anions of organic and inorganic acids showed very high tolerance limit. Effect of various foreign ions on extraction of $\mathrm{Fe}(\mathrm{III})$ is summarized in Table 1.

\section{Separation of iron(III) from ternary mixtures}

Separation of $\mathrm{Fe}(\mathrm{III})$ from ternary mixtures containing commonly associated metal ions such as $\mathrm{Fe}(\mathrm{II}), \mathrm{Bi}(\mathrm{II}), \mathrm{Mn}(\mathrm{II}), \mathrm{Co}(\mathrm{II})$ and $\mathrm{Ni}(\mathrm{II})$ was carried out by taking advantage of the differences in the extraction conditions of metal ions. The flow chart (figure 5) shows the conditions for quantitative separation of these metal ions from mixture.

\section{Analysis of iron(III) from soap samples}

The proposed method was employed for the analysis of iron(III) in soaps available in local market. The known amount of soap was digested with $25 \mathrm{~mL}$ of concentrated hydrochloric acid and the resulting mixture was evaporated to dryness. The procedure was repeated for trice and then solution was extracted with distilled deionised water. The extracted solution was filtered using whatmann filter paper No.1, washings are collected and used for the further analysis. An aliquot sample solution was analyzed by AAS for determination of exact concentration of iron in given sample. Then Fe(III) from aliquot sample was extracted and determined as per the proposed method. The results were in good agreement with those obtained with AAS as shown in Table 2.

Table 1. Effect of various foreign ions

\begin{tabular}{|c|c|c|c|c|c|}
\hline Ion & Added as & $\begin{array}{l}\text { Tol. } \\
\text { Limit* } \\
\text { (mg) }\end{array}$ & Ion & Added as & $\begin{array}{l}\text { Tol. } \\
\text { Limit* } \\
\text { (mg) }\end{array}$ \\
\hline $\mathrm{Li}^{+}$ & $\mathrm{LiCl}$ & 5 & $\mathrm{Al}^{3+}$ & $\mathrm{Al}_{2}\left(\mathrm{SO}_{4}\right)_{3} .16 \mathrm{H}_{2} \mathrm{O}$ & 10 \\
\hline $\mathrm{Na}^{+}$ & $\mathrm{NaCl}$ & 15 & $\mathrm{Zr}^{4+}$ & $\mathrm{Zr}\left(\mathrm{NO}_{3}\right)_{4} .4 \mathrm{H}_{2} \mathrm{O}$ & 10 \\
\hline $\mathrm{K}^{+}$ & $\mathrm{KCl}$ & 10 & $\mathrm{~V}^{4+}$ & $\mathrm{VOSO}_{4} .4 \mathrm{H}_{2} \mathrm{O}$ & 5 \\
\hline $\mathrm{Cr}^{6+}$ & $\mathrm{K}_{2} \mathrm{Cr}_{2} \mathrm{O}_{7}$ & 2 & $\mathrm{Be}^{2+}$ & $\mathrm{BeSO}_{4} .4 \mathrm{H}_{2} \mathrm{O}$ & 5 \\
\hline $\mathrm{Ca}^{2+}$ & $\mathrm{CaCl}_{2}$ & 2 & $\mathrm{Mg}^{2+}$ & $\mathrm{MgCl} .6 \mathrm{H}_{2} \mathrm{O}$ & 15 \\
\hline $\mathrm{Ba}^{2+}$ & $\mathrm{Ba}\left(\mathrm{NO}_{3}\right)_{2}$ & 5 & $\mathrm{Hg}^{2+}$ & $\mathrm{HgCl}_{2}$ & 5 \\
\hline $\mathrm{Co}^{2+}$ & $\mathrm{CoCl}_{2} \cdot 6 \mathrm{H}_{2} \mathrm{O}$ & 2 & $\mathrm{~Pb}^{2+}$ & $\mathrm{Pb}\left(\mathrm{NO}_{3}\right)_{2}$ & 2 \\
\hline $\mathrm{Ni}^{2+}$ & $\mathrm{NiCl}_{2} \cdot 6 \mathrm{H}_{2} \mathrm{O}$ & 2 & $\mathrm{Cr}^{3+}$ & $\mathrm{Cr}\left(\mathrm{NO}_{3}\right)_{3} .9 \mathrm{H}_{2} \mathrm{O}$ & 5 \\
\hline $\mathrm{Mn}^{2+}$ & $\mathrm{MnCl}_{2 .} 4 \mathrm{H}_{2} \mathrm{O}$ & 5 & $\mathrm{Br}^{-}$ & $\mathrm{HBr}$ & 5 \\
\hline $\mathrm{Zn}^{2+}$ & $\mathrm{ZnCl}_{2}$ & 5 & $\mathrm{SCN}^{-}$ & $\mathrm{NH}_{4} \mathrm{SCN}$ & 5 \\
\hline $\mathrm{Cd}^{2+}$ & $\mathrm{CdCl}_{2}$ & 1 & $\mathrm{ClO}_{4}^{-}$ & $\mathrm{HClO}_{4}$ & 15 \\
\hline $\mathrm{Sn}^{2+}$ & $\mathrm{SnCl}_{2}$ & 5 & Acetate & Acetic acid & 5 \\
\hline $\mathrm{Cu}^{2+}$ & $\mathrm{CuCl}_{2} .2 \mathrm{H}_{2} \mathrm{O}$ & 1 & $\mathrm{SO}_{4}{ }^{2-}$ & $\mathrm{H}_{2} \mathrm{SO}_{4}$ & 5 \\
\hline $\mathrm{PO}_{4}^{3-}$ & $\mathrm{H}_{3} \mathrm{PO}_{4}$ & 15 & $\mathrm{BO}_{3}{ }^{3-}$ & $\mathrm{H}_{3} \mathrm{BO}_{3}$ & 5 \\
\hline Oxalate & Oxalic acid & 5 & Tartrate & Tartaric acid & 5 \\
\hline Ascorbate & Ascorbic acid & 15 & EDTA & EDTA & 10 \\
\hline
\end{tabular}

Table 2. Analysis of iron(III) from soap samples 


\begin{tabular}{llll}
\hline & Soap sample & Amount of Iron(III) (\%) & \\
\cline { 3 - 4 } & & By AAS & Proposed method \\
\hline 1. & Ghadi & 0.70 & 0.67 \\
2. & Nirama & 0.85 & 0.82 \\
3. & Wheel & 0.67 & 0.63 \\
\hline * average of triplicate analysis & &
\end{tabular}

* average of triplicate analysis

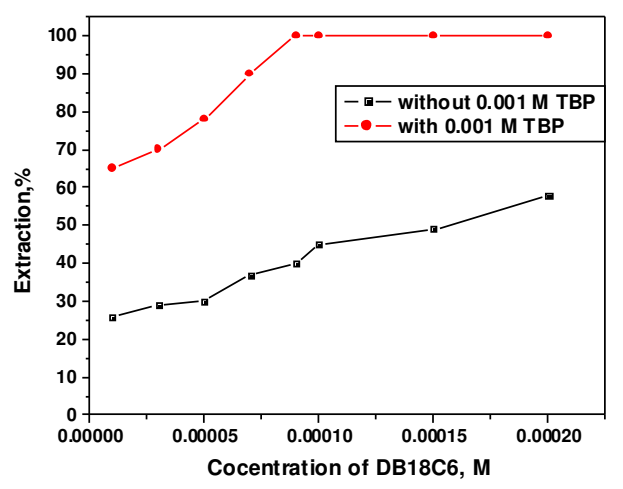

Figure 1. Effect of DB18C6 concentration on solvent extraction of Fe(III)

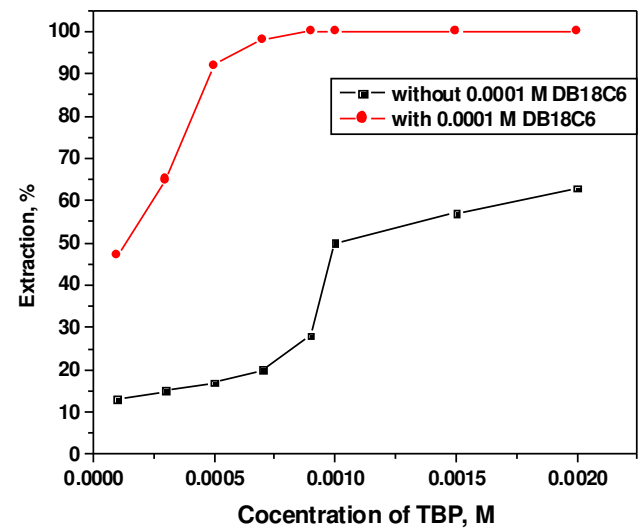

Figure 2. Effect of TBP concentration on solvent extraction of Fe(III)

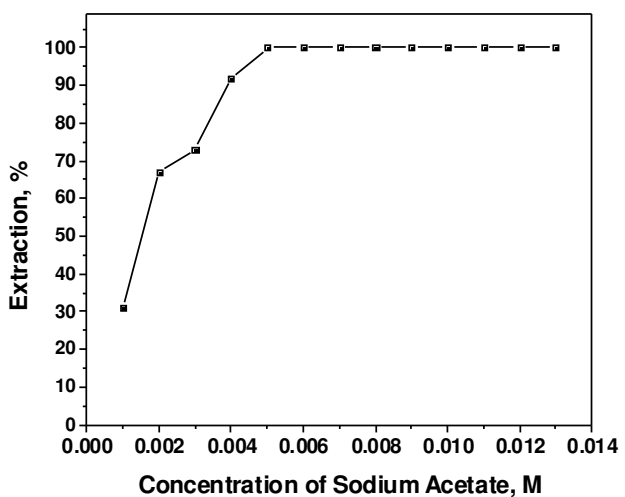

Figure 3. Effect of sodium acetate concentration on solvent extraction of Fe(III) 


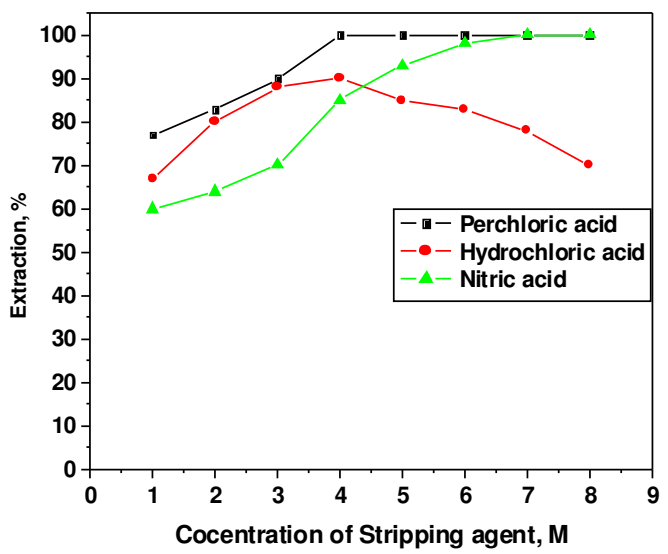

Figure 4. Effect of stripping agents

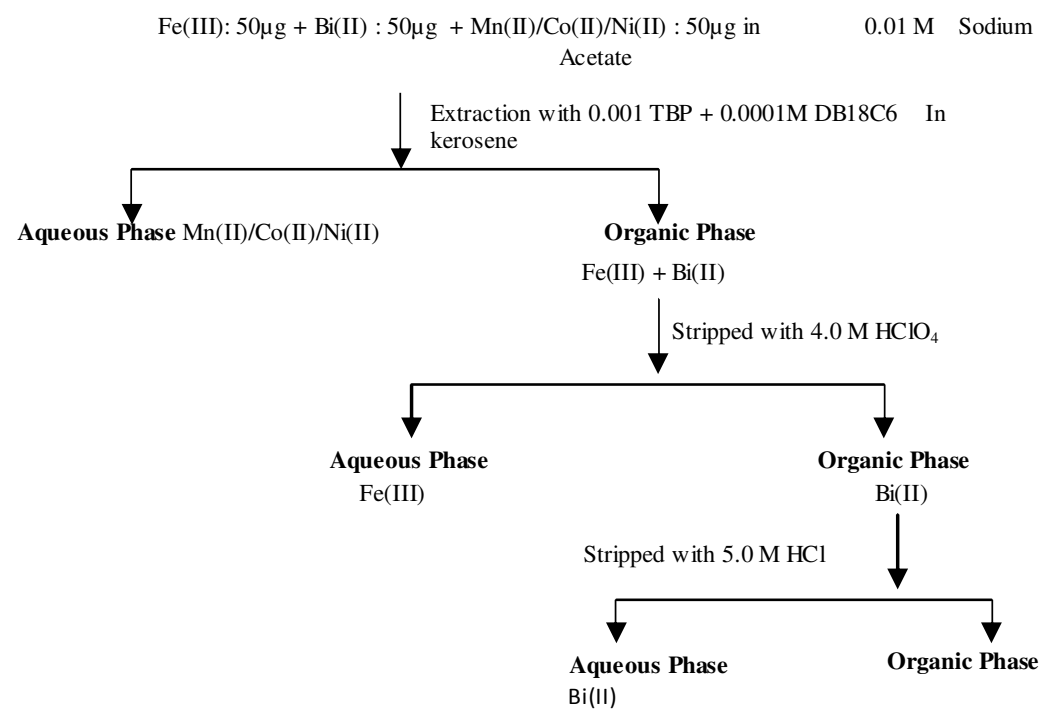

Figure 5. Separation of $\mathrm{Fe}(\mathrm{III})$ from multicomponent mixture

\section{Conclusions:}

Synergistic liquid-liquid extraction and separation method for iron(III) from sodium acetate medium using DB18C6 and TBP in kerosene has been studied. The method is simple, rapid and selective having good reproducibility (approximately $\pm 2 \%$ ). Advantages of this method over previous method is that, mixture of extractants containing low concentration of DB18C6 and TBP was sufficient for quantitative extraction of $\mathrm{Fe}(\mathrm{III})$, kerosene available in local market is used as solvent and less affect of foreign ions on extraction efficiency. Extractive separation method proposed is simple and provides a reliable means for the selective and sequential separation of iron(III) when present in various matrices and commercial samples.

\section{Acknowledgment:}

Authors are thankful to UGC for minor research project grant [47-205/11 (WRO)] and DST for FIST grant.

\section{References:}

1. Beata P., Wladyslaw W., Michal J. W., Physicochem. Probl. Miner. Process., 39 (2005) 89.

2. Costa M. C., Carvalho A., Uryga A., Paiva A. P., Solvent Extr. Ion Exch., 21(5) (2003) 653.

3. Naik M. T., Dhadke P. M., J. Chem. Eng. Data, 44 (1999) 1037. 
4. Norasikin O., Masahiro G., Hanapi M., Jurnal Teknologi, 42(F) (2005) 25.

5. Van de Voorde I., Latruwe K., Pinoy L., Courtijn E., Solvent Extr. Ion Exch., 25 (2007) 809.

6. Sandhibigraha A., Bhaskara Sarma P.V. R., Chakravartty V., Scand. J. Metall., 25(3) (1996) 135

7. Akash D., Paulo F. M., Jorge M. R., Ind. Eng. Chem. Res., 46 (2007) 5707.

8. Sahu K. K., Das R. P., Metall. Mater. Trans. B, 28B (1997) 181.

9. Sahu K. K., Das R. P., Metall. Mater. Trans. B, 31B, (2000) 1169 .

10. Pospiech B., Walkowiak W., Physicochem. Probl. Miner. Process., 44 (2010) 195.

11. Akash D., Paulo F. M., Jorge M. R., Ind. Eng. Chem. Res., 45 (2006) 3200.

12. Keng $\mathbf{X}$., Kun H., Lin $\mathbf{X}$., Pinhua $\mathbf{Y}$., Liangrong Y., Huizhou L., Ind. Eng. Chem. Res., 50 (2011) 6362.

13. Jayachandran J., Dhadke P.M., Talanta, 44 (1997) 1285.

14. Lupi C., Pilone D., Hydrometallurgy, 57 (2000) 201.

15. Biswas R. K., Begum D. A., Hydrometallurgy, 50 (1998) 153.

16. Biswas R. K., Begum D. A., Hydrometallurgy, 54 (1999) 1.
17. Biswas R. K., Begum D. A., Hydrometallurgy, 60 (2001) 81.

18. Saji J., Reddy M. L. P., Hydrometallurgy 61 (2001) 81.

19. Saji J., Prasad R. T., Iyer C. S. P., Reddy M. L. P., Hydrometallurgy, 49 (1998) 289.

20. Gupta B., Deep A., Singh V., Tandon S. N., Hydrometallurgy, 70 (2003) 121.

21. Cierpiszewski, R., Miesia I., RegelRosocka M., Sastre, A. M., Szymanowski J., Ind. Eng. Chem. Res., 41 (2002) 598.

22. Grzeszczak A., Regel-Rosocka M., Hydrometallurgy, 86 (2007) 72.

23. Regel-Rosocka, M., Szymanowski J., Solv. Extr. Ion Exch., 23 (2005) 41

24. Abraham W., Avraham P., Rami K., Sarah E., Hydrometallurgy, 49 (1) (1979) 93.

25. Zouhri A., Burgard M., Lakkis D., Hydrometallurgy, 38 (3) (1995) 299.

26. Hideko K., Hiroshi O., Anal. Sci., 1 (1985) 389.

27 A.I. Vogel, A textbook of quantitative inorganic analysis including elementary instrumental analysis, The English language book society and Longman, 3rd edition, (1975) 523.

28. Overstone T. C., Parker C. A., Anal. Chim. Acta., 3 (1949) 277. 